\title{
Evidence Update: A Summary of New Evidence to Inform Treatment Decisions for Patients with Meniscal
}

\section{Lesions}

Simon G.F. Abram ${ }^{1,2}$; David J. Beard ${ }^{1,2}$; Caroline B. Hing ${ }^{3}$; Andrew J. Price , $^{1,2}$

1. Nuffield Department of Orthopaedics, Rheumatology and Musculoskeletal Sciences (NDORMS), University of Oxford, Oxford, UK

2. National Institute for Health Research (NIHR) Biomedical Research Centre, Oxford, UK

3. St George's University London, St George's University Hospitals NHS Foundation Trust, London, UK

This month, to support treatment decisions for patients with meniscal lesions, the BASK Meniscal Working Group reports new national guidance in The Bone \& Joint Journal.[1] This is the culmination of more than two-years of work supported by BASK, the NHS Getting It Right First Time (GIRFT) programme, and National Institute for Health Research (NIHR). A summary of the new evidence produced from this programme is summarised in Table 1.

Although a number of randomised controlled trials (RCTs) have investigated the effectiveness of arthroscopic partial meniscectomy (APM), $[2-10]$ the correct interpretation of the evidence has been controversial. There has been some decline in the rate of APM since 2013 in England but with a high level of regional variation in intervention rate.[11] APM is still commonly performed in patients over the age of 60 -years but national data suggests variation in selection criteria and 10-fold regional variation in the proportion of patients receiving a subsequent knee arthroplasty within 1year of APM.[12]

To develop evidence-based guidance, a new systematic review was required to summarise the RCT evidence.[13] In this review, the evidence applicable to different groups of patients stratified according to important clinical and radiological criteria was determined.[13] This review was recently published in The British Journal of Sports Medicine.[13] Perhaps the most important finding was that no trial has been performed (or registered) in patients with a radiologically confirmed unstable meniscal lesion with corresponding meniscal symptoms, nor in patients failing a period of appropriate physiotherapy.[13] In all the published RCTs, relatively non-specific selection criteria were applied: patients with knee pain and any pattern of meniscal lesion. Nevertheless, a greater benefit from APM in comparison to physiotherapy was found at 6-12 months (pain, function, knee-specific quality of life) in patients with a meniscal lesion without osteoarthritis in comparison to patients with coexistent osteoarthritis.[13] In RCTs of APM versus physiotherapy, up to $30 \%$ of patients subsequently chose to undergo APM, confounding the intention-to-treat analyses, but suggesting that first line non-operative treatment may be appropriate for the majority of these patients.[13] Another systematic review of patient-reported outcome measures (PROMs), published in BMJ Open, concluded that current evidence is limited by the lack of a well validated PROM for use in this population.[14] The minimum clinically important difference (MCID) in outcome scores for these patients is still unknown and PROMs might not truly reflect the symptoms, function and quality of life of patients with meniscal lesions.[14]

The balance of benefit and risk must be carefully considered in the context of shared-decision making.[15] Previous studies have attempted to investigate the short-term risk associated with undergoing knee arthroscopy but have had a number of limitations such as small patient numbers, combining major and minor arthroscopic procedures in a single cohort, a narrow range of complications evaluated, and inconsistent or limited data sources.[16] For low-risk procedures, 
it is also important to consider the possibility that any subsequent adverse events may be incidental and not directly attributable to undergoing the procedure itself. In The Lancet, we recently reported the risk of adverse events following APM in a cohort of 700,000 patients.[17] At least one serious adverse event (pulmonary embolism [PE], myocardial infarction, stroke, fasciotomy, neurovascular injury, infection requiring surgery, or death) occurred in $0.3 \%$ of patients within 90-days of APM but few of these complications occurred more frequently than in comparative general population data.[17] PE and septic arthritis were observed at a higher rate following APM than in the general population: corresponding to one attributable PE and two infections for every 1500 APM procedures performed.[17]

To standardise treatment selection decisions, it is important that consistent terminology is used when describing different patients. This was not previously possible for patients with meniscal lesions as there was no agreement on the terminology to be used, nor the important symptoms, signs, and radiological findings in this population. The delivery of standardised terminology was one of the first priorities of the BASK Meniscal Working Group and the output from this consensus work was published recently in The Knee.[18] The clinical and radiological findings believed to be important when considering treatment selection for patients with meniscal lesions were generated, refined, and agreed.[18] These terms were the foundation for the evaluation of all the clinical evidence and development of the new guidance.

Evidence-based treatment guidance should inform on treatment "appropriateness" in clearly defined clinical scenarios. No formal "treatment appropriateness" exercise had previously been performed for patients with meniscal lesions. In part, this is because such an exercise requires standardised terminology and a clear understanding of the evidence for anticipated benefits and harms that may be associated with undergoing the intervention. With this new information, the BASK Meniscal Working Group used the established RAND/UCLA Appropriateness Method (RAM)[19] to produce treatment recommendations that form the basis of the new guidance. The document stratifies patients based upon symptoms, signs, radiological findings, duration of symptoms, and previous treatment history. Forty-five simulated clinical scenarios were refined to five common clinical presentations and corresponding treatment recommendations. The guidance developed was found to be acceptable to the members of BASK (following consultation of the BASK membership, $97 \%$ of respondents agreed to practice according to the document recommendations) and also members of a patient involvement group. The document is endorsed by both BASK and the NHS Getting It Right First Time (GIRFT) programme. Adoption and validation in clinical practice is now required. 


\begin{tabular}{|c|c|c|}
\hline Aim / Research Question & Reference & Summary of key findings \\
\hline $\begin{array}{l}\text { What were the trends in APM intervention rate over } \\
\text { the last } 20 \text {-years? How might this have been } \\
\text { influenced by the publication of new evidence? In } \\
\text { which age-groups is APM most commonly } \\
\text { performed? }\end{array}$ & [11] & $\begin{array}{l}\text { Overall, APM rates increased } 130 \% \text { over the } \\
\text { last } 20 \text {-years. } \\
\text { There has been a partial decline in intervention } \\
\text { rate since } 2013 \text {, likely in response to the } \\
\text { publication of new clinical trial evidence. } \\
\text { APM was most commonly performed in } \\
\text { patients aged } 40-59 \text {-years, followed by } 60-79- \\
\text { years, in 2016/17. }\end{array}$ \\
\hline $\begin{array}{l}\text { What is the } 1 \text {-year rate of arthroplasty following } \\
\text { APM, by patient age-group, and is there regional } \\
\text { variation in this treatment outcome? }\end{array}$ & [12] & $\begin{array}{l}\text { In patients who underwent APM over the age } \\
\text { of } 60 \text {-years, } 10 \% \text { subsequently underwent } \\
\text { arthroplasty within one-year. } \\
\text { There was greater than } 10 \text {-fold variation in the } \\
\text { rate of subsequent arthroplasty by CCG. }\end{array}$ \\
\hline $\begin{array}{l}\text { What is the clinical trial evidence for the } \\
\text { effectiveness of APM in patient groups stratified } \\
\text { according to the important clinical and radiological } \\
\text { patient selection factors? }\end{array}$ & {$[13]$} & $\begin{array}{l}\text { - Greatest improvement in pain, function, and } \\
\text { quality of life was observed following APM } \\
\text { (versus physiotherapy) in patients without } \\
\text { osteoarthritis. } \\
\text { - Patients meeting the latest, strict, clinical and } \\
\text { radiological selection criteria for APM are not } \\
\text { represented by the current evidence. } \\
\text { - No study has been limited to the inclusion of } \\
\text { patients who have failed non-surgical } \\
\text { treatment. }\end{array}$ \\
\hline $\begin{array}{l}\text { Are available PROMs valid for use in patients with } \\
\text { meniscal tears? }\end{array}$ & [14] & $\begin{array}{l}\text { - The evidence supporting the validity of } \\
\text { PROMs in patients with meniscal tears is of } \\
\text { poor quality and incomplete. } \\
\text { - Further work is required to determine the best } \\
\text { PROMs to record pain, function, quality of life, } \\
\text { in this population. }\end{array}$ \\
\hline $\begin{array}{l}\text { What is the true risk associated with undergoing } \\
\text { APM? }\end{array}$ & {$[17]$} & $\begin{array}{l}\text { Risk associated with undergoing APM is low. } \\
\text { - No attributable risk of mortality, myocardial } \\
\text { infarction, stroke. } \\
\text { Some rare but serious complications must be } \\
\text { considered: including pulmonary embolism } \\
\text { and infection. }\end{array}$ \\
\hline $\begin{array}{l}\text { Is there expert agreement on the clinical and } \\
\text { radiological selection criteria that are important when } \\
\text { considering treatment options for patients with } \\
\text { meniscal tears? How should these criteria be } \\
\text { consistently defined? }\end{array}$ & {$[18]$} & $\begin{array}{l}\text { - Standardised terminology was agreed. } \\
\text { - Symptoms were defined and classified into } \\
\text { three groups: (1) strongly suggestive of a } \\
\text { treatable meniscal lesion, (2) potentially } \\
\text { suggestive of a treatable meniscal lesion, (3) } \\
\text { osteoarthritic. } \\
\text { Meniscal lesions and tear patterns on MRI } \\
\text { imaging were defined and classified with } \\
\text { reference to potential treatability: (1) target, (2) } \\
\text { possible target, (3) no target. }\end{array}$ \\
\hline $\begin{array}{l}\text { From the latest evidence, when is arthroscopic } \\
\text { meniscal surgery appropriate? When should } \\
\text { alternative treatments be recommended? }\end{array}$ & {$[1]$} & $\begin{array}{l}\text { - Arthroscopic meniscal surgery should not be } \\
\text { performed in patients with advanced } \\
\text { osteoarthritis except in rare special cases. } \\
\text { Most patients presenting with a meniscal lesion } \\
\text { and symptoms should first undergo at least } 3 \\
\text { months of non-operative treatment. } \\
\text { - For patients not responding to this non- } \\
\text { operative treatment, meniscal surgery may be } \\
\text { beneficial and should be considered. } \\
\text { - Urgent surgery may be indicated for patients } \\
\text { with a locked knee. Meniscal repair should be } \\
\text { considered in patients with a repairable } \\
\text { meniscal tear following an acute injury. }\end{array}$ \\
\hline
\end{tabular}




\section{Funding statement:}

This report is independent research supported by the National Institute for Health Research (NIHR Doctoral Research Fellowship, Mr Simon Abram, DRF-2017-10-030) and NIHR Oxford Biomedical Research Centre (BRC). The views expressed in this publication are those of the authors and not necessarily those of the NHS, the National Institute for Health Research, or the Department of Health and Social Care. 


\section{REFERENCES}

[1] Abram SGF, Beard DJ, Price AJ. Arthroscopic meniscal surgery: a national society treatment guideline and consensus statement from the BASK Meniscal Working Group. Bone Jt J 2019; In Press. doi:10.1302/0301620X.101B6.BJJ-2019-0126.R1.

[2] Herrlin S, Hållander M, Wange P, Weidenhielm L, Werner S. Arthroscopic or conservative treatment of degenerative medial meniscal tears: A prospective randomised trial. Knee Surgery, Sport Traumatol Arthrosc 2007;15:393-401. doi:10.1007/s00167-006-0243-2.

[3] Katz JN, Brophy RH, Chaisson CE, de Chaves L, Cole BJ, Dahm DL, et al. Surgery versus physical therapy for a meniscal tear and osteoarthritis. N Engl J Med 2013;368:1675-84. doi:10.1056/NEJMoa1301408.

[4] Osteras H, Osteras B, Torstensen TA. Medical Exercise Therapy is Effective After Arthroscopic Surgery of Degenerative Meniscus of the Knee: A Randomized Controlled Trial. J Clin Med Res 2012;4:378-84. doi:10.4021/jocmr1100w.

[5] Yim J-H, Seon J-K, Song E-K, Choi J-I, Kim M-C, Lee K-B, et al. A comparative study of meniscectomy and nonoperative treatment for degenerative horizontal tears of the medial meniscus. Am $\mathrm{J}$ Sports Med 2013;41:1565-70. doi:10.1177/0363546513488518.

[6] Gauffin H, Tagesson S, Meunier A, Magnusson H, Kvist J. Knee arthroscopic surgery is beneficial to middleaged patients with meniscal symptoms: a prospective, randomised, single-blinded study. Osteoarthr Cartil 2014;22:1808-16. doi:10.1016/j.joca.2014.07.017.

[7] Kise NJ, Risberg MA, Stensrud S, Ranstam J, Engebretsen L, Roos EM. Exercise therapy versus arthroscopic partial meniscectomy for degenerative meniscal tear in middle aged patients: randomised controlled trial with two year follow-up. BMJ 2016;354:i3740. doi:10.1136/bmj.i3740.

[8] Graaf VA van de, Noorduyn JCA, Willigenburg NW, Butter IK, Gast A de, Mol BW, et al. Effect of Early Surgery vs Physical Therapy on Knee Function Among Patients With Nonobstructive Meniscal Tears: The ESCAPE Randomized Clinical Trial. JAMA 2018;320:1328-37. doi:10.1001/JAMA.2018.13308.

[9] Vermesan D, Prejbeanu R, Laitin S, Damian G, Deleanu B, Abbinante A, et al. Arthroscopic debridement compared to intra-articular steroids in treating degenerative medial meniscal tears. Eur Rev Med Pharmacol Sci $2013 ; 17: 3192-6$.

[10] Roos EM, Hare KB, Nielsen SM, Christensen R, Lohmander LS. Better outcome from arthroscopic partial meniscectomy than skin incisions only? A sham-controlled randomised trial in patients aged 35-55 years with knee pain and an MRI-verified meniscal tear. BMJ Open 2018;8:1-10. doi:10.1136/bmjopen-2017-019461. 
[11] Abram SGF, Judge A, Beard DJ, Wilson HA, Price AJ. Temporal trends and regional variation in the rate of arthroscopic knee surgery in England: analysis of over 1.7 million procedures between 1997 and 2017. Has practice changed in response to new evidence? $\mathrm{Br} \mathrm{J}$ Sports Med 2018:bjsports-2018-099414. doi:10.1136/bjsports-2018-099414.

[12] Abram SGF, Judge A, Beard DJ, Price AJ. Rates of knee arthroplasty within one-year of undergoing arthroscopic partial meniscectomy in England: temporal trends, regional and age-group variation in conversion rates. Osteoarthr Cartil 2019;In Press. doi:10.1016/j.joca.2019.03.009.

[13] Abram SGF, Hopewell S, Monk AP, Bayliss LE, Beard DJ, Price AJ. Arthroscopic partial meniscectomy for meniscal tears of the knee: A systematic review and meta-analysis. Br J Sports Med 2019:bjsports-2018-100223. doi:10.1136/bjsports-2018-100223.

[14] Abram SGF, Middleton R, Beard DJ, Price AJ, Hopewell S. Patient-reported outcome measures for patients with meniscal tears: a systematic review of measurement properties and evaluation with the COSMIN checklist. BMJ Open 2017;7:e017247. doi:10.1136/bmjopen-2017-017247.

[15] Chan SW, Tulloch E, Cooper ES, Smith A, Wojcik W, Norman JE. Montgomery and informed consent: where are we now? BMJ 2017;2224:j2224. doi:10.1136/bmj.j2224.

[16] Thorlund JB, Juhl CB, Roos EM, Lohmander LS. Arthroscopic surgery for degenerative knee: systematic review and meta-analysis of benefits and harms. BMJ 2015;350:h2747-h2747. doi:10.1136/bmj.h2747.

[17] Abram SGF, Judge A, Beard DJ, Price AJ. Adverse outcomes after arthroscopic partial meniscectomy: a study of 700000 procedures in the national Hospital Episode Statistics database for England. Lancet 2018;392:2194202. doi:10.1016/S0140-6736(18)31771-9.

[18] Abram SGF, Beard DJ, Price AJ. National consensus on the definition, investigation, and classification of meniscal lesions of the knee. Knee 2018;25:834-40. doi:10.1016/j.knee.2018.06.001.

[19] Fitch K, Bernstein SJJ, Aguilar MDD, Burnand B, LaCalle JRR, Lazaro P, et al. The RAND / UCLA Appropriateness Method User's Manual. 2001. 